\title{
Uterine contractile activity in rats induced by mifepristone (RU 486) in relation to changes in concentrations of prostaglandins E-2 and F-2 $\alpha$
}

\author{
W. Arkaravichien and K. E. Kendle \\ School of Pharmacy, Robert Gordon Institute of Technology, Aberdeen AB9 IFR, UK
}

\begin{abstract}
Summary. Pregnant rats were injected with mifepristone (RU 486) on Day 15 of pregnancy. The force and frequency of uterine contractions, recorded by a microballoon technique, were significantly greater at 12,24 and $36 \mathrm{~h}$ in treated than in control rats $(11.9 \pm 1.9$ vs. $8.9 \pm 1.2$ units, $17.7 \pm 3.0$ vs. $10.5 \pm 2.3$ units and $16.8 \pm 2.9$ vs. $8.8 \pm 1.8$ units for force and $51.3 \pm 9 \cdot 1$ vs. $29.4 \pm 3.8 / \mathrm{h}, 35.4 \pm 6.4$ vs. $22 \cdot 1 \pm 4.9 / \mathrm{h}$ and $35.6 \pm 3 \cdot 2$ vs. $24 \cdot 6 \pm 4 \cdot 6 / \mathrm{h}$ for frequency, respectively). There was no significant difference in concentrations of prostaglandin (PG) E- 2 or PGF-2 $\alpha$ between treated and control rats at $12 \mathrm{~h}$ and $24 \mathrm{~h}$ after injection. At $36 \mathrm{~h}, 7$ of 12 rats were aborting and uterine $\mathrm{PG}$ concentrations in these were significantly greater than in the others $(1.5 \pm 0.2$ vs. $0.9 \pm 0.2 \mathrm{ng} \mathrm{PGE}-2 / \mathrm{g}$ and $38.6 \pm 19.2$ vs. $16.9 \pm 5.4 \mathrm{ng}$ PGF $-2 \alpha / \mathrm{g})$, but there was no significant difference between control and treated rats that were not aborting. Concentrations of PGE-2 and PGF- $2 \alpha$ were significantly higher at $48 \mathrm{~h}$ when abortion had occurred in all animals $(6.5 \pm 2.6$ vs. $2.4 \pm 1.7 \mathrm{ng}$ PGE- $2 / \mathrm{g}$ and $30.4 \pm 8.9$ vs. $9 \cdot 3 \pm 5.6 \mathrm{ng}$ PGF $-2 \alpha / \mathrm{g}$ ). Thus, the increase in uterine contractile activity induced by mifepristone preceded significant changes in concentrations of PGE-2 and PGF- $2 \alpha$ in the uterus and so could not have been caused by these changes.
\end{abstract}

Kelwords: uterine contractions; prostaglandins; mifepristone; rat

\section{Introduction}

Mifepristone (RU 486) is an antiprogestin which acts predominantly on progesterone receptors in the endometrium and induces an increase in myometrial activity (Baulieu, 1985). Kelly et al. (1986) have demonstrated that mifepristone stimulates production of prostaglandins (PG) E-2 and F-2 $\alpha$ by stromal cells in human endometrial cells in culture. Mifepristone also antagonizes the inhibitory action of progesterone on PG production in isolated human endometrial cells in culture (Kelly \& Smith, 1987) and in cultured rat myometrial explants (Jeremy \& Dandona, 1986). Evidence in several species shows that uterine activity is increased by PGs and their analogues (Karim \& Filshie, 1970; Whalley \& White, 1980a, b; Dubin et al., 1982; Wainman et al., 1988). Swahn \& Bygdeman (1988) have shown that the increase in human uterine contractile activity induced by mifepristone is enhanced by co-administration of the prostaglandin analogue 16-phenoxy PGE-2, but it is not known whether the increase in activity induced by mifepristone is mediated by prostaglandin(s). This study investigated whether there is any association between uterine contractile activity and the change of concentrations of PGE- 2 and PGF- $2 \alpha$ in the uterus after administration of mifepristone in rats.

\section{Materials and Methods}

Animals and treatment. Female Sprague-Dawley rats aged 9-13 weeks housed as described by Kendle (1975) were paired with males and examined daily for evidence of successful mating. The day of a positive sperm smear was 
defined as Day 1 of pregnancy. Mated rats were randomly allocated to receive subcutaneous injections of sesame oil (Sigma, St Louis, MO, USA; control group) or $2 \mathrm{mg}$ mifepristone (Roussel Laboratory, Swindon, UK)/kg in sesame oil (treated group) on Day 15 of pregnancy. The animals were killed and the uteri removed for the determination of uterine PGE-2 and PGF-2 $\alpha$ at 12,24,36 and $48 \mathrm{~h}$ after treatment. Other groups of rats were used for determination of uterine contractile activity at 12,24 and $36 \mathrm{~h}$ after injection. The numbers of rats in each treatment group are shown in Figs $I$ and 2 .

Uterine prostaglandins. The rats were killed by cervical dislocation, the abdomens were opened and the uteri were quickly removed and put into ethanol to stop enzyme function. The time taken from killing the rats to placing the uterine tissue in ethanol was $<1 \mathrm{~min}$. Each uterus was cut open longitudinally, the fetuses and placentae were removed and the uterine tissue was left in ethanol for $10 \mathrm{~min}$. The tissue was blotted dry and weighed and then kept at $-20^{\circ} \mathrm{C}$ until extraction.

The extraction of uterine prostaglandins was as described by Poyser (1988). Briefly, tissue was homogenized in ethanol, evaporated to dryness, redissolved in water, adjusting the $\mathrm{pH}$ to $3 \cdot 5-4 \cdot 0$, extracted with ethyl acetate, evaporated and redissolved in an exact volume of ethyl acetate before being kept at $-20^{\circ} \mathrm{C}$ until assay. Percentage recovery was determined by adding radiolabelled PGE- 2 and PGF- $2 \alpha$ to tissue and then extracting by the same procedure. Recoveries of 88.3 and $87.5 \%$ were obtained for PGE-2 and PGF-2 $\alpha$, respectively, and sample values were corrected accordingly.

Prostaglandin concentrations were determined by radioimmunoassay (RIA), using antibody for PGE-2 from Advance Magnetic Inc. (Massachusetts, USA) and antibody for PGF-2 $\alpha$ from Poyser's laboratory, Department of Pharmacology, Edinburgh University, UK. The interassay and intra-assay coefficients of variation were $9 \cdot 1$ and $8.9 \%$ for PGE-2 and 6.3 and $9 \cdot 6 \%$ for PGF-2 $\alpha$, respectively.

Recording uterine contractile activity. The rats were anaesthetized with $60 \mathrm{mg}$ sodium pentobarbitone $/ \mathrm{kg}$ (M\&B, Dagenham, UK) subcutaneously. The ovarian end of the uterine horn was gently pulled out through a flank incision and a tiny incision was made on the antimesometrial wall. Three fetuses and their placentae were removed after puncturing the amniotic sacs. A microballoon (IVP 57, Biomedix, UK) connected to a 6-cm polyethylene tube (i.d. $0.6 \mathrm{~mm}$ and o.d. $0.8 \mathrm{~mm}$ ) was inserted into the uterine horn, then the tube was connected to a pressure transducer (Eclomatic EM 750). The uterus was sutured, the microballoon was inflated with $0.2 \mathrm{ml}$ saline solution and the uterus was placed back into the abdominal cavity. After allowing the uterus to stabilize for $1 \mathrm{~h}$, intra-uterine pressure was recorded for $2 \mathrm{~h}$ using a Washington oscillograph (MD20). The force of contraction, assumed to be proportional to the amplitude of the intra-uterine pressure waves, was expressed in arbitrary units derived from measurements of wave amplitude.

Statistical analysis. Concentrations of PGE-2 and PGF-2 $\alpha$ in the uterus were calculated as ng/g of tissue and expressed as means \pm s.d.; differences in the concentrations between control and treated groups at each time point were analysed by Student's $t$ test. Uterine contractile activity was determined as the frequency of contraction and average force of contraction (units); Student's $t$ test was used to determine the significance of differences between treated and control groups at each time point.

\section{Results}

Uterine concentrations of PGE-2 at 12 and $24 \mathrm{~h}$ after injecting with mifepristone or vehicle were not significantly different (Fig. 1). At $36 \mathrm{~h}$ after injection, 7 of 12 rats were in the process of abortion and the concentration of PGE-2 in this subgroup was slightly, but significantly, higher than in control rats. The uterine PGE-2 concentrations were not significantly different in rats that were not aborting and control rats. At $48 \mathrm{~h}$, all treated rats were aborting and uterine concentrations of PGE-2 were significantly higher than those in the control group.

The changes in uterine PGF- $2 \alpha$ concentration were similar in pattern to those of uterine PGE-2 concentration. There was no significant difference in PGF- $2 \alpha$ concentration between treated and control rats at 12 and $24 \mathrm{~h}$; but concentrations at $36 \mathrm{~h}$ in the aborting rats and at $48 \mathrm{~h}$ in the treated rats were significantly higher than those in control rats.

At $36 \mathrm{~h}$ after injection with mifepristone, three of nine rats were aborting, but there was no significant difference in the force or frequency of contractions between rats that were or were not aborting, so the data were pooled (Fig. 2). The force and frequency of contraction were significantly higher in treated than in control rats at every time point.

Recording of uterine contractions at $48 \mathrm{~h}$ after treatment was considered unnecessary because significant increases had already been shown at the three earlier time points after administration of mifepristone. 

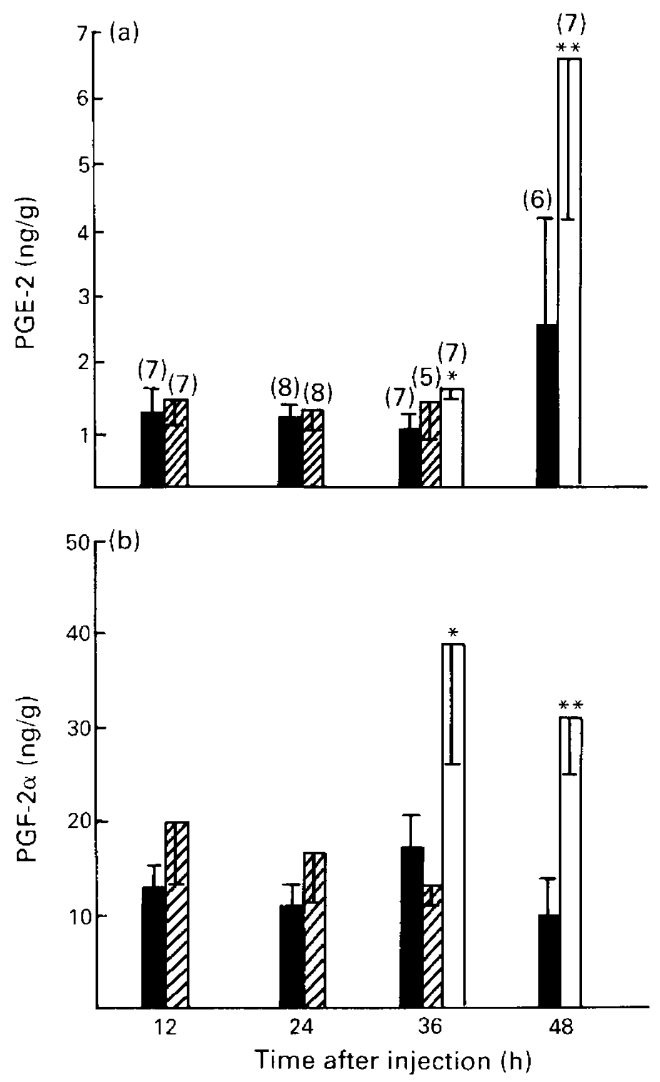

Fig. 1. Concentrations (means \pm s.d.) of prostaglandins (PG) (a) E-2 and (b) F-2 $\alpha$ in uteri at $12,24,36$ and $48 \mathrm{~h}$ after injection of pregnant rats with vehicle (control, $\boldsymbol{\square}$ ) or mifepristone ( $\mathbb{Z}$, not aborting; $\square$, aborting) on Day 15 ; numbers in parentheses are numbers of rats in each group. Significantly different from the control at the same time point at ${ }^{*} P<0.05$ and $* * P<0.01$.

\section{Discussion}

This study showed that a single injection of mifepristone to pregnant rats on Day 15 causes an increase in the force and frequency of uterine contractions and an increase in uterine concentrations of PGE-2 and PGF-2 $\alpha$. The increase of uterine contractile activity occurred earlier than the increase in uterine PGE-2 and PGF-2 $\alpha$. The study of uterine contractile activity was, necessarily, observed in rats in which intra-uterine microballoons had been placed surgically at least $1 \mathrm{~h}$ previously. Because trauma is known to increase production of PGs (Peek et al., 1987), concentrations of PGs were determined in tissues of animals in which no surgical trauma had been inflicted. It can be argued, however, that this design means that the results of the two experiments are not comparable and that the time of increased PG production may be different in animals that had undergone surgery. This argument is most unlikely, as the effect of trauma on PG production is known to be transient (Poyser \& Riley, 1987), baseline production being re-established within $10 \mathrm{~min}$. Furthermore, the present study showed that the changes in contractile activity induced by mifepristone do not occur in vehicle-treated animals and must therefore be attributed to the treatment rather than to any effect of surgery. It is considered unlikely that surgical trauma more than $1 \mathrm{~h}$ earlier would have had an effect on the drug-induced increase in PG production. 

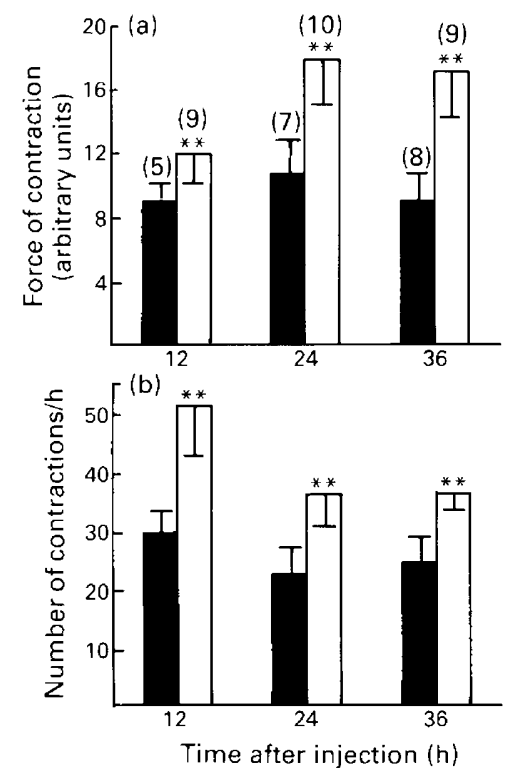

Fig. 2. (a) Force and (b) frequency (means \pm s.d.) of uterine contraction at 12,24 and $36 \mathrm{~h}$ after injection of pregnant rats with vehicle (control, $\mathbf{\square}$ ) or mifepristone ( $\square$ ) on Day 15 ; numbers in parentheses are numbers of rats in each group. ${ }^{* *}$ Significantly different from the control at the same time point $(P<0.01)$.

The rises of PGE-2 and PGF-2 $\alpha$ in this study were first detected at $36 \mathrm{~h}$ after injection of mifepristone. This delay is similar to that reported by Kelly et al. (1986) in human endometrial cells in culture, in which no significant stimulation of PGE-2 or PGF-2 $\alpha$ by mifepristone occurred during the first $24 \mathrm{~h}$ of incubation, but there was significant stimulation of PG production during the second 24-h of incubation. Similarly, the antagonistic effect of mifepristone on progesterone inhibition of PG production in human secretory endometrial cells was seen on Day 3 of culture, but not on the first 2 days (Kelly \& Smith, 1987). The mechanism by which antiprogestin causes an increase in PG production is not fully understood; it may be by stimulating endogenous synthesis of PGs or by inhibiting PG catabolism (Kelly et al., 1986). It is possible that antiprogestin displaces the progesterone bound to cytosolic receptors and then inhibits the induction of $40 \mathrm{kDa}$ protein, which, in turn, stimulates phospholipase activity, as proposed by Thorburn (1985). This may explain the delay before the changes of uterine PGs were seen.

The increase in uterine $\mathrm{PG}$ concentrations at $36 \mathrm{~h}$ after administration of mifepristone was seen only in rats that were aborting. Also, the rise in PG concentrations at $48 \mathrm{~h}$ was from the uteri of the aborting rats. This finding supports the hypothesis that PGs may have an important role in the expulsion of the fetuses, which explains the significant rises in uterine PG concentrations at parturition (Strauss et al., 1975; Wilson \& Freinkel, 1982; Wilson et al., 1982).

It is obvious that the increase in uterine PGE-2 and PGF- $2 \alpha$ concentrations occurred much later than the increase in uterine contractile activity. Therefore, the increase in uterine contractile activity induced by mifepristone could not have been mediated by changes in uterine PGE-2 and PGF-2 $\alpha$ concentrations, but is believed to be a direct effect on the myometrium when progesterone is displaced. There are a number of findings to support this hypothesis. Intrauterine infusion of PGF-2 $\alpha$, which elicited a marked mechanical uterine response in oestrogen-treated ovariectomized ewes, failed to stimulate the uteri which had been pre-blocked by progesterone, suggesting that the inhibition produced by progesterone was due to a direct action of the hormone on the uterine muscle and not to an indirect mechanism operating through uterine PGs (Lye \& Porter, 1978). The clinical finding that adjuvant $\mathrm{PG}$ therapy was required to obtain a high frequency of complete 
abortion indicated that, if endogenous PGs were important for the appearance of co-ordinated uterine contractions, they were not always sufficiently effective to cause expulsion of the conceptus (Bygdeman \& Swahn, 1985). Also, it has been demonstrated that progesterone induces refractoriness to excitation, through a reduction of $\mathrm{Ca}^{2+}$ mobility (Currie \& Jeremy, 1979), increased myometrial membrane potential and blocked propagated membrane activity (Goto \& Csapo, 1959; Marshall, 1959).

Although the study showed that the mifepristone-induced increase in uterine contractile activity occurs at least $24 \mathrm{~h}$ earlier than changes in prostaglandins in the tissue, it may be argued that concentration in the tissue is a poor indicator of the concentration in a receptor compartment. This could mean that increases in concentrations in the receptor compartment could trigger responses before any change in concentration in the whole uterine tissue was apparent. This possibility is most unlikely, as Poyser (1988) has demonstrated that concentrations in uterine tissue are an accurate reflection of PG production rates and the biological half-lives of PGs are known to be short. The work of Wilson \& Huang (1983) also indicated that uterine prostaglandins were good indicators of $\mathrm{PG}$ production under circumstances in which uterine venous plasma concentrations were not. Furthermore, if high local concentrations of PGs were retained in a receptor compartment and only slowly equilibrated with the tissue as a whole, it would be expected that in-vitro responses would be prolonged and that washout of exogenous PGs would be slow; this is not the case. Myometrial contractions induced by PGs in vitro can be terminated easily and quickly by washing out the bathing media (Foreman et al., 1987) or by adding indomethacin (Phillips \& Poyser, 1981).

This study demonstrated that administration of a single dose of mifepristone $(2 \mathrm{mg} / \mathrm{kg})$ s.c. to pregnant rats on Day 15 causes an increase in uterine contractile activity and an increase in uterine PGE-2 and PGF-2 $\alpha$, but shows, for the first time, that the increase in uterine contractile activity induced by mifepristone occurs much earlier than the changes in uterine PGE-2 and PGF-2 $\alpha$ concentrations.

We thank Dr Poyser for a gift of anti-serum for PGF-2 $\alpha$, the Scottish Antibody Production Unit for rabbit serum and anti-rabbit $\operatorname{IgG}$, and Roussel for mifepristone.

\section{References}

Baulieu, E.E. (1985) RU 486: an antiprogestin steroid with contragestive activity in women. In The Antiprogestin Steroid RU 486 and Human Fertility Control, pp. 1-25. Eds E. E. Baulieu \& S. J. Segal. Plenum Press, New York.

Bygdeman, M. \& Swahn, M.L. (1985) Progesterone receptor blockage: effect on uterine contractility in early pregnancy. Contraception 32, 45-5I .

Currie, W.B. \& Jeremy, J.Y. (1979) In vitro actions of progesterone on mammalian myometrium-reversible modulation of the resistance of the rabbit uterus to excitation contraction coupling. Biol. Reprod. 22. 945-952.

Dubin, N.H., Blake, D.A., Ghodgaonkar, B.R. \& Egner, P.G. (1982) Thromboxane B2, 6-keto-prostaglandin $F 1 \alpha$, and prostaglandin $F 2 \alpha$ production by contracting pregnant rat uteri in vivo. Biol. Reprod. 26, 281-288.

Foreman, D., Zuk, L., Miller, D.B. \& Salomon, R.G. (1987) Effects of E2-levuglandins on the contractile activity of the rat uterus. Prostaglandins 34, 91-98.

Goto, M. \& Csapo, A. (1959) The effect of the ovarian steroids on the membrane potential of uterine muscle. J. Gen. Physiol. 43, 455-466.
Jeremy, J.Y. \& Dandona, P. (1986) RU 486 antagonizes the inhibitory action of progesterone on prostacyclin and thromboxane $\mathrm{A} 2$ synthesis in cultured rat myometrial explants. Endocrinology 119, 655-660.

Karim, S.M.M. \& Filshie, G.M. (1970) Use of PGF-2 $\alpha$ for therapeutic abortion. Br. Med. J. 3, 198-200.

Kelly, R.W., Healy, D.L., Cameron, I.T. \& Baird, D.T. (1986) The stimulation of prostaglandin production by two antiprogesterone steroids in human endometrial cells. J. Clin. Endocr. Metab. 62, $1116-1123$.

Kelly, R.W. \& Smith, S.K. (1987) Progesterone and antiprogestins: a comparison of their effect on prostaglandin production by human secretory phase endometrium and decidua. Prostaglandins Leukotrienes Med. 29, 181-186.

Kendle, K.E. (1975) Some biological properties of RMI 12936 a new synthetic antiprogestational steroid. $J$. Reprod. Fert. 43, 505-513.

Lye, S.J. \& Porter, D.G. (1978) Demonstration that progesterone blocks uterine activity in the ewe in vivo by a direct action on myometrium. $J$. Reprod. Fert. 52, 87-94.

Marshall, J.M. (1959) Effect of estrogen and progesterone on sample uterine muscle fibers in the rat. $\mathrm{Am} . J$. Physiol. 197, 935-942. 
Peek, M.J., Norman, T.M., Morgan, C., Fraser, I.S. \& Markham, R. (1987) Trauma induced human endometrial prostaglandin concentrations. Prostaglandins 34, 919--925.

Phillips, C.A. \& Poyser, N.L. (1981) Prostaglandins, thromboxanes and the pregnant rat uterus at term. Br. J. Pharmacol. 73, 75-80.

Poyser, N.L. \& Riley, S.C. (1987) Effect of actinomycin $\mathrm{D}$ on prostaglandin synthesis by and output from the guinea-pig uterus. Prostaglandins Leukotriens Med. 28, 153-168.

Poyser, N.L. (1988) Tissue levels of prostaglandins and what do they mean? Studies on the guinea-pig uterus. Prostaglandins 36, 645-653.

Strauss, J.F., Sakoloski, J., Caploe, P., Duffy, P., Mintz, G. \& Stambaugh, R.L. (1975) On the role of prostaglandins in parturition in the rat. Endocrinology $\mathbf{9 6}$, $1040-1043$.

Swahn, M.L. \& Bygdeman, M. (1988) The effect of antiprogestin RU 486 on uterine contractility and sensitivity to prostaglandin and oxytocin. $B r . J$. Obstet. Gynaecol. 95, $126-134$.

Thorburn, D.G. (1985) Prostaglandins and the regulation of myometrial activity: a working model. In The Physiological Development of the Fetus and Newborn, pp. 381-393. Eds C. T. Jones \& P. W. Nathanielsz. Academic Press, London.
Wainman, B.C., Burcea, I. \& Crankshaw, D.J. (1988) The effect of prostanoids on estrogen-dominated rat myometrial longitudinal muscle in vitro. Biol. Reprod. 39, 221-228.

Whalley, P.J. \& White, S.K. (1980a) Comparison of various prostaglandins on the in vitro longitudinal uterine smooth muscle of the rat and guinea-pig. $\mathrm{Br}$. J. Pharmacol. 68, 150-151.

Whalley, P.J. \& White, S.K. (1980b) Effect of PGF-2 $\alpha$, PGE-2 and ICI 81008 on the in vitro and in vivo uterus on non-pregnant rats and guinea-pigs. $\mathrm{Br}$. $J$. Pharmacol. 69, 309.

Wilson, L. \& Freinkel, N. (1982) Alterations in uterine and placental prostaglandin $\mathrm{F}$ and $\mathrm{E}$ with gestational age in the rat. Prostaglandins 24, 567-574.

Wilson, L., Stanisc, D., Dawood, F.K. \& Dawood, M.Y. (1982) Alterations in reproductive tissue prostaglandin $\mathrm{E}$ and $\mathrm{F}$, 6-keto-prostaglandin $\mathrm{Fl} \alpha$ and thromboxane $\mathbf{B} 2$ with gestational age in the rat. Biol. Reprod. 27, 1207-1215.

Wilson, L. \& Huang, L.S. (1983) Effects of the fetalplacental unit on uterine prostaglandin levels at term in the pregnant rat. Prostaglandins 25, 725-731.

Received 29 October 1990 